\title{
IMPACTOS DA JUSTIÇA TRANSICIONAL SUL- AMERICANA NO SISTEMA INTERAMERICANO DE DIREITOS HUMANOS
}

\author{
Isabela Gerbelli Garbin Ramanzini \\ é Doutora em Relações Internacionais (IRI-USP), Fellow do Carr Center for Human Rights \\ Policy, Harvard Kennedy School e Professora da Universidade Federal de Uberlândia (UFU). \\ Uberlândia, MG, Brasil.E-mail: <isabelagarbin@hotmail.com> \\ http://dx.doi.org/10.1590/0102-261284/103
}

\section{Introdução ${ }^{1}$}

A maioria dos Estados sul-americanos esteve sob o comando de regimes ditatoriais entre as décadas de 1970 e 1980, período que singularizou a história regional pelas diversas violações de direitos humanos praticadas de forma sistemática como políticas de Estado. Os processos de transição democrática foram - e continuam sendo, em muitos casos bastante diversos em termos do tratamento estatal conferido aos prismas da justiça, da verdade e da reparação. Entretanto, um denominador comum entre aqueles que lutam pela predominância dos valores democráticos na região consiste no receio à impunidade. O enfrentamento aos passados autoritários na América do Sul experimentou uma diversidade de métodos e práticas, judiciais (processos criminais) e não judiciais (comissões da verdade, por exemplo), conduzidos tanto no plano doméstico, quanto no internacional.

\footnotetext{
1 Agradeço os comentários e sugestões de Kathryn Sikkink, Rossana Rocha Reis, Bruno Boti Bernardi e Marcelo Torelly a este texto.
} 
No âmbito internacional, o Sistema Interamericano de Direitos Humanos (SIDH) teve um papel significativo para a justiça transicional nas Américas. Arquitetado em momento anterior à instauração de ditaduras militares, o sistema desenvolveu-se, desde o início, centrado no ideal democrático (Acevedo; Grossman, 1996; Sikkink, 2014). Com a implementação de seu primeiro órgão em 1959, a Comissão Interamericana de Direitos Humanos (CIDH), o sistema regional encontra os elementos formais iniciais para lidar com os abusos de direitos humanos cometidos pelas ditaduras vigentes. Contudo, um enfrentamento objetivo destas violações, pautado em processos institucionais, somente se verifica nos anos 2000, com a formação de uma jurisprudência própria no assunto. Se as violações de direitos humanos decorrentes de passados autoritários foram - e são - tão representativas para a realidade de direitos humanos da região, quais razões explicam a demanda de quase 262 quatro décadas para o SIDH enfrentar, de forma objetiva, os casos de justiça de transição nas Américas?

Os estudos sobre as normas globais - os quais tangenciam temas de justiça de transição - evoluíram tanto no entendimento dos atores (redes transnacionais de advocacy) e dos mecanismos (padrão bumerangue, cascata de justiça) que promovem transformação no comportamento estatal, quanto nos impactos da normativa internacional e dos atores transnacionais sobre os governos/Estados (Finnemore; Sikkink, 1988; Lutz; Sikkink, 2000; Sikkink; Walling, 2010). Esta literatura nos dá elementos para compreender o porquê, embora os Estados nem sempre reconheçam as normas e decisões internacionais, em especial as de direitos humanos, cada vez mais se torna crescente a demanda e a referência às mesmas. Além disso, nos estudos mais específicos sobre justiça de transição, a avaliação dos processos internacionais revela que os Tribunais Internacionais têm sido elementos fundamentais para criar novos incentivos aos processos domésticos 
(Sikkink, 2005). Em que pese o avanço destes trabalhos, verificamos poucas análises que procuram identificar como e em que medida as próprias instituições internacionais também podem ser impactadas pelas normas globais. Destas, as relativas à justiça de transição são um bom caso para se analisar o impacto institucional, pois ao lidarem com os valores da justiça, da verdade e da reparação individual, acabam por transformar, em última análise, a essência estatal nos sistemas internacionais de direitos humanos, prevalecente na vontade política ou responsabilidade subsidiária estatal em dar cumprimento às decisões internacionais, por exemplo.

Neste ponto, pretendemos verificar o modo pelo qual o SIDH se posicionou perante a questão da justiça transicional na América do Sul e quais os resultados deste processo para o próprio sistema. Para cumprir esse objetivo, o trabalho se estrutura do seguinte modo: na primeira seção, faremos uma retrospectiva do desenvolvimento institucional do SIDH como forma de entender os avanços institucionais do regime de direitos humanos ao longo de sua existência. Na seção seguinte, adentraremos, em específico, no tratamento interamericano em relação à justiça transicional. $\mathrm{Na}$ seção final, contrabalancearemos a perspectiva adotada com dados sobre o desenvolvimento dos processos domésticos internos de enfrentamento aos passados autoritários e a consolidação das redes transnacionais de advocacy na região. Em seguida, passaremos às considerações finais.

\section{Sistema Interamericano de Direitos Humanos: trajetória institucional}

O Sistema Interamericano de Direitos Humanos tem como objetivo principal regular a região no que se refere à observância dos padrões internacionais de direitos humanos. Encontra-se vinculado à Organização dos Estados Americanos (OEA), instituição multifuncional que engloba uma complexa estrutura de normas e instituições. Uma 
revisão da trajetória normativa e institucional - balanceada com noções da conjuntura internacional - revela que o sistema regional se desenvolveu com base e em reação aos obstáculos (políticos, financeiros, institucionais) interpostos pelos Estados da região e pela própria OEA. Pretendemos demonstrar que, nas diversas contendas, o SIDH mostrou habilidade em explorar eventuais janelas de oportunidade para ultrapassar os limites institucionais originários, as pressões estatais e os constrangimentos estruturais da OEA, de modo a buscar autonomia para levar adiante suas missões e seus interesses, no sentido de se manter como uma instância apta a conduzir as questões relativas aos direitos humanos no âmbito regional (Cavallaro; Brewer, 2008; Goldman, 2009; Engstrom; Hurell, 2010; Thede; Brisson, 2011). Esta seção, portanto, analisa os principais movimentos institucionais tendentes a modificar funções e atividades dos órgãos interamericanos como forma de ampliar as garantias de responsabilização estatal frente às violações de direitos humanos.

Como a literatura aponta, o SIDH erige de uma base normativa bastante frágil (Carta da OEA e Declaração Americana de Direitos Humanos, ambas de 1948), mas suficientemente genérica para permitir um desenvolvimento normativo e institucional que poucos poderiam prever (Medina, 1990; Buergenthal, 2005). Essa idiossincrasia permite considerar que a intenção inicial de alguns Estados e da própria OEA quanto ao futuro do SIDH poderia ser apenas retórica, decorrente das aspirações de reconstrução do pós-Segunda Guerra Mundial. Contudo, as tensões políticas no Caribe e, sobretudo, a Revolução Cubana durante a Guerra Fria demandaram à OEA a previsão de meios formais para garantir a manutenção da ordem "democrática”, ainda que, na prática, isso significasse manter a região livre das investidas comunistas. Por meio da Resolução VIII de 1959, a OEA arquitetou a criação da Comissão Interamericana de Direitos Humanos (IDH), com a missão de promover os direitos 
humanos na região. Contando com um mandato vago e destinação orçamentária bastante restritiva, a Comissão IDH recebeu atribuições originárias muito limitadas, como a elaboração de estudos sobre as condições de direitos humanos nos Estados. Nesse exercício, o objetivo da CIDH não correspondia, necessariamente, à investigação de violações individuais; todavia, tanto a OEA quanto os Estados-membros não conseguiram antecipar alguns efeitos decorrentes dessa atividade inicial. $\mathrm{O}$ apelo normativo do órgão alcançou públicos domésticos vinculados às vítimas das violações de direitos humanos, pois tão logo se tomou conhecimento das atividades empreendidas pela CIDH, indivíduos começaram a enviar denúncias sobre violações de direitos humanos em seus Estados. Buscando legitimar de alguma forma a possibilidade de empreender esforços de proteção (e não apenas de promoção, conforme mandato originário), a Comissão IDH criou um procedimento para "tomar conhecimento" das denúncias individuais, tratando-as como fonte de informação para o registro das sistemáticas violações de direitos humanos na região. $\mathrm{O}$ amparo normativo para esta nova atividade decorria de uma autointerpretação extensiva do mandato da CIDH, realizada já na primeira sessão do órgão, em 1960. Ato contínuo, a Comissão IDH solicitou ao Conselho da OEA que tornasse explícito, por meio das normas regionais, estas ampliadas competências do órgão, que incluíam o poder de "tomar conhecimento", implicitamente já auto-assegurado pela CIDH (Goldman, 2009).

A competência para lidar com as denúncias individuais foi formalizada em 1965, por meio da Resolução XXII, documento que expandiu as funções e poderes da Comissão IDH, permitindo que o órgão pudesse "examinar", isto é, investigar e emitir opinião sobre violações individuais de direitos humanos. A estratégia da Comissão para transpassar a ausência de cooperação estatal nos processos de investigação e para ampliar sua abrangência para todos os 
direitos previstos na Declaração Americana foi interpretar a Resolução XXII da OEA em conjunto com o mandato inicial do órgão, firmando entendimento de que: a garantia do poder de "examinar" comunicações individuais não poderia diminuir o poder da Comissão de "tomar conhecimento" de denúncias sobre os demais direitos protegidos pela Declaração Americana (atribuído pelo mandato original) (Farer, 1997). Assim, a Comissão realizou tal manobra para preservar seus poderes amplos de identificar graves e sistemáticas violações de direitos humanos e, ao mesmo tempo, colher informações que pudessem amparar as denúncias individuais. Este movimento foi importante para o desenvolvimento institucional da Comissão IDH, pois o procedimento para "tomar conhecimento" mais tarde se transformou no processamento de casos contenciosos no SIDH. Todavia, com escassos recursos humanos e financeiros, a Comissão IDH se viu obrigada, por muito tempo, a 266 concentrar suas atividades no exame de situações gerais de direitos humanos nos Estados, deixando os casos individuais para segundo plano.

A transformação do SIDH num sistema protetivo dependeu da aprovação da Convenção Americana de Direitos do Homem (CADH), em 1969. Esta foi considerada o instrumento de direitos humanos mais ambicioso e amplo já desenvolvido por um sistema internacional de direitos humanos (Medina, 1990; Farer, 1997; Goldman, 2009), pois além de ampliar consideravelmente o conteúdo², modificou inequivocamente a estrutura do SIDH com a previsão de uma Corte regional. Na época da adoção da CADH, a maioria dos Estados sul-americanos se encontrava sob regimes ditatoriais, o que parece explicar a procrastinação da entrada em vigência deste tratado regional que previa

\footnotetext{
2 A CADH passou a incluir novos direitos civis e políticos (como o direito à indenização, o direito de retificação ou de resposta e o direito ao nome) e direitos econômicos e sociais (como o direito ao desenvolvimento progressivo).
} 
a criação de um órgão cuja função consistia em responsabilizar os governos por violações de direitos humanos - a Convenção somente entrou em vigência em 1978³.

Este momento coincide com o início de alguns dos processos de transição democrática na região, e ao mesmo tempo marcou um momento de transição para o formato final da CIDH. A previsão de estabelecimento de uma Corte regional colocou em xeque a exclusividade e a própria continuidade da Comissão em assuntos de direitos humanos na região. Antevendo riscos, a CIDH começou a delinear a versão de um novo Estatuto e Regulamento consistentes com uma interpretação própria e autointeressada dos dispositivos da $\mathrm{CADH}$, em que entendeu como única modificação promovida pela entrada em vigor da Convenção a adição de uma nova competência para o órgão, específica para atuar nos procedimentos contenciosos, em conjunto com a Corte IDH (Farer, 1997). Neste caso, a Comissão manejou tanto para subsistir como órgão do sistema regional, quanto para controlar as atividades da Corte IDH.

A Corte IDH levou dez anos para entrar em funcionamento, isso porque, como dito, a maior parte dos governos nas Américas Latina e Central, na época, estava sob comandos militares; não havia um ambiente favorável às instituições internacionais autoritativas de direitos humanos. $\mathrm{O}$ tribunal tinha capacidade originária para exercer dois tipos de funções: a competência contenciosa (julgamento e responsabilização) e a competência consultiva (interpretação e orientação). Entre 1979 e 1987 a Corte IDH centrou-se no objetivo interno de organização gradual ${ }^{4}$ de sua estrutura normativa e institucional, mesmo porque, após seu estabelecimento efetivo, a

\footnotetext{
3 A vigência da CADH teve início quando ratificada por 11 Estados: Colômbia, Costa Rica, El Salvador, Equador, Honduras, Haiti, Granada, Guatemala, Panamá, República Dominicana e Venezuela. Disponível em: <https://www.cidh.oas.org/ Basicos/Portugues/d.Convencao_Americana_Ratif..htm>. Acesso em: 4 abr. 2018).

4 Relatórios anuais da Corte IDH de 1980 a 1987. Disponível em: <http:/ /www.oas. org/es/cidh/informes/anuales.asp>. Acesso em: 4 abr. 2018.
} 
relação entre os órgãos interamericanos de direitos humanos não transcorreu em bases amistosas, muito em razão das desconfianças mútuas quanto à divisão de funções e poderes. Enquanto a CIDH relutava em enviar ao tribunal casos contenciosos, a Corte IDH trabalhou, basicamente, com poucas opiniões consultivas, propostas por Estados e pela Comissão. O tribunal se valeu da oportunidade de trabalho nas opiniões consultivas para: ampliar a abrangência de seu mandato para outros tratados internacionais ${ }^{5}$; chamar atenção da opinião pública internacional ${ }^{6}$; e firmar parceria com a CIDH para resolver casos de graves violações de direitos humanos, mesmo quando o Estado-denunciado não fosse parte da $\mathrm{CADH}^{7}$. A tendência de não envio de casos ao tribunal somente se modificou quando a Comissão passou a ser pressionada pelos comentaristas, advogados e governos (O'Donnel, 1986; Farer, 1997). Modificando gradualmente a sua postura, a nova frente de trabalhos da CIDH nos casos contenciosos transcorreu para268 lelamente às visitas in loco e relatorias estatais ainda que, sob a influência da nova competência, o foco dessas últimas atividades passou às relatorias temáticas ${ }^{8}$.

Estas relatorias constituíram um turning point para reconstituição da identidade deste órgão interamericano, uma vez que, por meio deste mecanismo, a CIDH entendeu que mantinha um papel único na região: o desenvolvimento de novos parâmetros substantivos sobre os direitos humanos; a articulação entre Estados, Organizações Não

\footnotetext{
${ }^{5}$ Na Opinião Consultiva no ${ }^{\circ}$, de 8 de setembro de 1983, a Corte IDH firmou entendimento extensivo de que poderia se referir a quaisquer outros tratados internacionais que a possibilitassem interpretar os instrumentos interamericanos. Disponível em: <http://www.corteidh.or.cr/docs/opiniones/seriea_03_esp.pdf > Acesso em: 28 ago. 2014.

${ }^{6}$ Em razão do Caso Schmidt, opinião consultiva no 5 de 13 de novembro de 1985 , que envolvia a discussão sobre liberdade de impressa em regimes democráticos.

7 Idem.

8 De 1990 até 2001, a CIDH mantém onze relatorias temáticas. A diversidade de temas trabalhados está disponível em: <http://www.oas.org/es/cidh/mandato/ relatorias.asp>. Acesso em: 16 mar. 2018.
} 
Governamentais (ONGs) e órgãos da OEA; e, a habilidade em chamar a atenção pública. Esta nova identidade da Comissão, reforçada pelo reconhecimento normativo de suas tarefas institucionais, permitiu que a ampla discricionariedade do órgão sobre a decisão de enviar casos à Corte IDH, exercida por mais de duas décadas, fosse revista em 2001. A partir deste momento, os papéis institucionais já se encontravam bastante definidos: a CIDH se ocupava das investigações e apurações formais iniciais das violações de direitos humanos, enquanto o tribunal concentrava suas atividades no julgamento dos casos.

Entre 1988 e 1994 a Corte IDH julgou seus primeiros casos, desenvolvendo rapidamente um conjunto de decisões sobre importantes aspectos substantivos e procedimentais do sistema interamericano ${ }^{9}$. Um dos motivos para a Corte dar ênfase nos casos contenciosos em detrimento das opiniões consultivas decorreu do interesse do tribunal em consolidar uma jurisprudência própria. O conjunto de entendimentos da Corte IDH chancelava costumes (que algumas vezes extrapolavam as competências originais) do tribunal, dando-lhe margem para atuar com um pouco mais de autonomia institucional. De 1998 até recentemente, desenvolveu-se a fase mais inovadora da Corte IDH: além da intensa produção jurisprudencial, o tribunal passou a empreender diversas reformas e parcerias estratégicas com os governos nacionais e grupos da sociedade civil organizada. Neste processo, a Corte renovou seus papéis, buscando maior legitimidade e autonomia institucional. A partir dos anos 2000, a Corte IDH se utilizou de reformas regulamentárias para reforçar a legitimidade perante organizações da sociedade civil internacional: abriu possibilidade de participação direta das vítimas e representantes em cada fase procedimental

\footnotetext{
9 Relatórios anuais da Corte IDH de 1988 a 1994. Disponível em: <http:/ /www. oas.org/es/cidh/informes/anuales.asp>. Acesso em: 28 ago. 2014.
} 
do julgamento ${ }^{10}$, solicitou a participação ativa destes grupos no processo de consulta sobre as reformas regulamentárias, criou um fundo de assistência legal às vítimas e a defensoria interamericana. Além disso, a Corte continuou a inovar por meio da jurisprudência ${ }^{11}$, dando interpretações extensivas e dinâmicas aos direitos civis e políticos de modo a enfrentar, indiretamente, questões coletivas relativas a direitos econômicos, sociais e culturais ${ }^{12}$. Neste momento também é que a Corte IDH avança mais diretamente sobre as questões da justiça de transição, temática em que a jurisprudência interamericana revela sua abordagem mais inovadora e expansiva da proteção dos direitos humanos (Neuman, 2008; Binder, 2011; Mejía-Lemos, 2014).

Em síntese, a sequência dos principais desdobramentos institucionais da CIDH e da Corte IDH revela que, diante de constrangimentos estruturais e conjunturais, ambos organismos agiram para modificar suas fun270 ções, papéis e identidades ao longo de suas existências, se valendo de autointerpretações extensivas e combinadas de seus mandatos, de uma série de reformas regulamentárias e de entendimentos jurisprudenciais expansivos para se manterem como instâncias aptas a lidar com as questões de direitos humanos no hemisfério. O caso das jurisprudências sobre justiça transicional mostra um novo avanço da Corte IDH, desta vez no sentido de transformar a responsabilização estatal (essência do sistema regional

\footnotetext{
${ }_{10}$ Antes dessa reforma, os peticionários não participavam diretamente no processamento do caso. Era a CIDH quem desempenhava o papel ambivalente de árbitro imparcial durante a fase de processamento perante a Comissão e parte oposta ao Estado-denunciado na fase de processamento perante a Corte IDH.

11 Uma das inovações mais importantes foi a adição da competência supervisora pela Corte IDH do cumprimento estatal de suas decisões. Neste sentido, ver Ramanzini (2014).

12 Nos últimos anos, a Corte IDH cumulou importantes decisões sobre discriminação por razões de orientação sexual, direitos das pessoas portadoras de deficiência, direitos de paternidade e direitos reprodutivos, entre outras.
} 
de direitos humanos) em responsabilização individual pela prática de violações de direitos humanos.

\section{Sistema Interamericano de Direitos Humanos: a justiça de transição}

Como observado na seção anterior, um dos obstáculos inerentes ao pleno funcionamento do SIDH, a princípio, decorre da intrincada relação com os governos ditatoriais da região. Afinal, o sistema regional, criado no impulso renovador pós-Segunda Guerra Mundial, haveria de lidar, inequivocamente, com uma série de violações sistemáticas de direitos humanos que se tornaram práticas comuns no hemisfério durante a Guerra Fria. O processo construído pelo SIDH para lidar com os crimes praticados durante as ditaduras militares revela que, para além do enfrentamento objetivo da causa, os resultados repercutem no próprio fortalecimento normativo e institucional do sistema regional. A apropriação (e permanência) da agenda da justiça de transição pelos órgãos interamericanos representa mais um elemento para se verificar formas pelas quais o sistema regional tem buscado autonomia para se manter como instância singular de interpretação e aplicação dos direitos humanos na região.

Uma narrativa sobre a questão da justiça transicional no SIDH pode ser sistematizada a partir dos objetivos perseguidos pelos órgãos interamericanos em dois momentos históricos distintos: a transição democrática e a consolidação democrática. Os marcos do eixo "transição democrática" abrangem desde os trabalhos iniciais da CIDH no assunto, enquanto ainda era instância única de direitos humanos na região, até o envolvimento direto da Corte IDH no tema por meio dos casos contenciosos. Já no eixo da "consolidação democrática", encontram-se contemplados a expansão dos parâmetros jurisprudenciais da Corte em termos quantitativos (spill over effect para outros casos/Estados) e qualitativos 
(abrangência dos julgados), bem como o atrelamento das questões/parâmetros transicionais a outros temas. Percebe-se, portanto, que a agenda da justiça transicional nas Américas sempre se fez presente no $\mathrm{SIDH}^{13}$, apesar do enfrentamento da questão nem sempre ter sido direto. Em que pese o argumento de que as atuais violações de direitos humanos na região ainda sejam reflexos dos passados autoritários (O’Donnel, 1986), existem razões de natureza diversa que também ajudam a explicar a manutenção desta agenda no sistema regional: o interesse institucional em expandir competências, funções e influências na região, consolidando uma ordem de direitos humanos pautada na $\mathrm{CADH}$. Eis o que pretendemos demonstrar a seguir.

Nos primeiros anos de atividade, o SIDH, ainda não organizado a partir da Convenção Americana, se deparou com sérios problemas de ordem conjuntural e institucional: de um lado, a maior parte dos Estados se encontrava 272 sob governos ditatoriais e, de outro, a CIDH, como único órgão de direitos humanos na região, contava com funções bastante limitadas ${ }^{14}$. Neste momento, a solução para lidar com as graves violações de direitos humanos praticadas pelos regimes militares operou-se via investigações in $l o c o^{15}$,

\footnotetext{
13 Neste ponto, cabe mencionar que as raízes do tema da justiça de transição na região podem até mesmo serem mais profundas e anteriores à institucionalização do sistema regional de direitos humanos. Sikkink (2014) propõe que o engajamento diplomático de Estados latino-americanos nos anos 1940, no que tange à inclusão do direito à justiça (baseados nas leis regionais de amparo ou tutela) nas normativas internacionais, sugere um protagonismo normativo do Sul em relação ao Norte Global.

14 Sobre a ingerência de membros de regimes militares na CIDH, Lima (2012, p. 196) nota que mesmo quando os membros da Comissão não estavam ligados aos regimes militares, a asfixia política no interior dos Estados era tanta que tornava até inadequada a submissão de casos individuais à CIDH, dado que os Estados não participavam de forma alguma da litigância, nem mesmo indicando provas para negar os fatos narrados.

15 A CIDH realizou investigações in loco no Chile em 1974 e na Argentina em 1976. Disponível em: <https://goo.gl/6DDLpe>. Acesso em: 16 mar. 2018.
} 
relatórios por país ${ }^{16}$ e relatórios anuais à $\mathrm{OEA}^{17}$, os quais não chegavam a imprimir uma tônica de responsabilização aos governos. Estes eram os meios disponíveis para documentar e legitimar as denúncias, de modo a expor e, de certa forma, desgastar internacionalmente as imagens dos ditadores. Mesmo diante das possibilidades reais de encerramento dos regimes militares na região - vislumbradas pela aprovação das leis de anistia ${ }^{18}$ - a posição do SIDH no assunto mostrava-se vacilante ${ }^{19}$.

No momento em que o SIDH se reestrutura a partir da Convenção Americana - e passa a contar com um aparato institucional um pouco mais definido - nenhum dos regimes autoritários da região era signatário desta norma. Após o início dos processos de reestabelecimento democrático, o ambiente se torna favorável à adoção não só da $\mathrm{CADH}$, como também de outras normas relevantes para o tratamento do tema, como a Convenção Interamericana contra a Tortura, de $1985^{20}$. Contudo, nesta fase, o SIDH acompanhou os processos políticos de tratamento do passado autoritário ainda dando primazia a mecanismos que não confrontavam diretamente as práticas estatais (Engstrom, 2011; Lima, 2012). Neste sentido, a Corte IDH encontrava-se limitada a

16 Relatórios de 1974, 1976 e 1977 sobre Chile e relatório de 1980 sobre a Argentina. Disponível em: <https://goo.gl/DzWcUa>. Acesso em: 16 mar. 2018.

17 Relatório Anual da CIDH 1979-1980. Disponível em: <https://goo.gl/BbsdaV >. Acesso em: 16 mar. 2018.

18 Vale notar que o momento da promulgação das leis de anistia variou entre os Estados: algumas anistias ocorreram antes do encerramento da ditadura militar (Brasil, Peru), outras durante a transição (Chile) e outras após a transição democrática (Argentina, Uruguai).

19 Evidência deste fato consta no Relatório de 1985-1986 da CIDH, que chegou a enunciar a legitimidade de algumas formas de anistia, quando os próprios responsáveis pelas violações as decretem previamente. Disponível em: <https://goo.gl/ XcixTa>. Acesso em: 16 mar. 2018.

20 Neste assunto, ver Moravcsik (2000). 
emitir pareceres consultivos relacionados ao habeas corpus $\mathrm{e}$ às garantias judiciais em estado de emergência ${ }^{21}$.

Esse tratamento ganha novos traços quando a Corte IDH passa a receber os primeiros casos contenciosos, momento que lança a oportunidade para o tribunal desenvolver uma doutrina de investigação e responsabilização por crimes cometidos nas ditaduras militares. Os entendimentos jurisprudenciais começam a ser elaborados no bojo do problema dos desaparecimentos forçados, em que a Corte declara que a impunidade representa por si só uma violação de direitos, exigindo a punição dos autores da violação ${ }^{22}$. Contudo, é importante salientar que, nestes julgamentos, a doutrina interamericana não faz conexão explícita entre os crimes cometidos e a responsabilização individual. A Corte IDH opta por relacionar a ausência de investigação criminal à fragilidade dos sistemas nacionais de justiça e não propriamente à existência de obstáculos estatais deliberadamente implementa274 dos para impedir a responsabilização individual nos casos de violações perpetradas por regimes autoritários (Lima, 2012).

Na década de 1990, o SIDH passou a dar passos mais largos rumo ao enfrentamento das violações cometidas pelos militares. A Comissão emitiu em 1992 um parecer onde declarou a inconsistência das leis de anistia com a proteção dos direitos humanos ${ }^{23}$. Essa posição foi questionada por parte da Argentina e do Uruguai, mediante opinião consultiva à Corte IDH no ano seguinte, vez que os Estados questionavam a competência do órgão para fazer declarações sobre as leis domésticas. A década também ficou marcada pelo avanço no substrato normativo regional a envolver questões refe-

${ }^{21}$ Pareceres Consultivos da Corte IDH no 8/87, de 30 de janeiro de 1987 e no 9/87, de 6 de outubro de 1987, respectivamente. Disponível em: <https://goo.gl/ dbz4b8>. Acesso em: 16 mar. 2018.

${ }^{22}$ Caso contencioso Velásquez Rodríguez vs. Honduras. Disponível em: <https:// goo.gl/9oYFnw>. Acesso em: 16 mar. 2018).

${ }^{23}$ Relatório no 29/92 da CIDH sobre o Uruguai. Disponível em: <https:/ /goo.gl/ DzWcUa>. Acesso em: 16 mar. 2018. 
rentes ao passado autoritário, com a adoção da Convenção Interamericana sobre o Desaparecimento Forçado, em 1994. Em 1997 também houve um implemento normativo quanto às obrigações democráticas dos Estados da região, providenciado pelo Protocolo de Washington à Carta da OEA.

É somente nos anos 2000 que ocorre uma grande virada no tratamento da justiça transicional pelo SIDH: há o enfrentamento direto de casos contenciosos cujo objeto remete aos crimes ditatoriais; expande-se, consideravelmente, a interpretação da CADH no assunto; e consolidam-se julgados condenatórios em diversos Estados sul-americanos, formando uma jurisprudência que congrega todos e cada um dos Estados da região. Por meio do julgamento de casos paradigmáticos, a Corte IDH afirmou a invalidade das leis de anistia e a obrigação de punir (Barrios Altos v. Peru e La Cantuta vs. Peru), firmando um forte precedente de que esses tipos de lei impedem a responsabilização de indivíduos, o conhecimento da verdade e a reparação de vítimas e familiares.

A vedação da anistia extravasou para outros casos nos anos seguintes, forjando, com o passar dos anos, um quadro completo de tratamento da justiça transicional entre os Estados sul-americanos ${ }^{24}$. Dentre os contenciosos mais significativos, destacam-se Bulacio vs. Argentina, em que a Corte IDH expande qualitativamente os limites da jurisprudência no assunto, afirmando

a obrigação de punir todas as violações de direitos humanos - e não apenas as graves e sistemáticas - a rejeição a qualquer instituto jurídico - não só aqueles citados no caso

\footnotetext{
${ }^{24}$ A vedação da anistia foi ressaltada diretamente em casos tratando da Guatemala (Myrna Mack Chang, Massacre Plan de Sánchez, Carpio Nicolle e outros, Massacre de las dos Erres), El Salvador (Hermanas Serrano Cruz, Contreras e outros), Suriname (Comunidade Moiwana), Uruguai (Gelman) e Brasil (Gomes Lund e outros) (<https://goo.gl/2VMGyZ>, acesso em: 16 mar. 2018).
} 
Barrios Altos - que sejam identificados como obstáculos para a punição e a prioridade dos direitos das vítimas se confrontados com os direitos do réu (Basch, 2007, p. 207).

Dessa forma, a regra de responsabilidade criminal individual não está ligada apenas aos casos de violações graves e sistemáticas, mas expande-se a qualquer ofensa de direitos enunciados na CADH. Atualmente, tampouco o entendimento da investigação e punibilidade individual ficou adstrito às questões da democracia, havendo se expandido para liberdade de expressão, liberdade de imprensa, disputas territoriais e condições precárias de detenção. Mais recentemente, o caso Almonacid Arellano vs. Chile dá início à inovadora doutrina de controle de convencionalidade, que pretende obrigar juízes nacionais a deixar de aplicar disposições legais domésticas (refratárias de um passado autoritário) em desconformidade com a CADH e com as interpreta276 ções/decisões da Corte IDH. Nesse caso, a inovação se opera via descentralização do controle da Convenção, tradicionalmente exercido pelo tribunal interamericano, de modo que essa decisão promove efeitos para além dos casos julgados. Assim, a Corte passa a exercer influência nos Estados, independentemente de um julgamento prévio.

Analisando-se a trajetória traçada pelos órgãos do SIDH para lidar com a justiça transicional seria possível afirmar que a CIDH e, sobretudo, a Corte IDH cumpriram papéis essenciais na busca pela reparação, pela verdade e pela responsabilização individual, tendo declarado os princípios gerais de tratamento no assunto e, de certa forma, estabilizado parâmetros normativos regionais, dando apoio aos esforços nacionais na luta contra a impunidade (Torelly, 2013). De outro lado, críticos ponderam que foi exatamente no desenvolvimento da jurisprudência interamericana sobre justiça de transição que se criou um modus operandi mais inovador e (muito mais) expansivo das competências da Corte (Binder, 
2011; Mejía-Lemos, 2014). Todavia, a expansão de funções e competências dos órgãos interamericanos a partir da temática da justiça de transição não representa, necessariamente, uma exceção dentro da trajetória institucional mais ampla do SIDH (Ramanzini, 2014). Pelo contrário, avaliamos que a justiça transicional foi encarada como mais uma oportunidade para que o SIDH pudesse se afirmar, com relativa segurança, como instância apta a lidar, cada vez mais autonomamente, com as questões de direitos humanos na região.

\section{Processos domésticos e Redes de Advocacy nos casos de justiça transicional}

Pelas duas seções anteriores buscamos demonstrar que os órgãos interamericanos de direitos humanos somente avançam, de forma inequívoca, na sensível questão da justiça de transição quando atingem um nível de institucionalidade razoável, a qual pode ser entendida pela instituição da Corte IDH e subsequente divisão de competências entre a CIDH e o tribunal, pelo desenvolvimento de uma jurisprudência específica no assunto e, pelo estabelecimento de marcos normativos correlatos à transição e consolidação democrática. Para controlar o peso da variável internacional (SIDH) na análise, estabeleceremos aqui breves considerações sobre os processos domésticos de justiça de transição (programas de reparação, comissões da verdade e processos penais internos) e sobre o estabelecimento das redes de advocacy na região.

Conforme exposto anteriormente, os constrangimentos da Guerra Fria e a fragilidade do sistema regional de direitos humanos impuseram um bloqueio nas alternativas internacionais para lidar com as graves e sistemáticas violações de direitos humanos cometidas pelos governos militares na América Latina, em especial na América do Sul. Sem sólido respaldo internacional à epoca, empreenderam-se diferentes formas de lidar domesticamente com a presença e os 
legados autoritários, ainda que sob o imperativo das leis de anistia $^{25}$. Em geral, um dos primeiros esforços constituiu nos programas de reparação às vítimas, os quais visaram oferecer certa contrapartida financeira como forma de promover uma sutil justiça entre vítimas e anistiados. Na América do Sul, Argentina, Brasil e Chile optaram, em momentos históricos distintos, por estes mecanismos (Torelly, 2013). Em seguida, tornaram-se métodos comuns as comissões da verdade, grupos oficiais que tinham como objetivo inicial reunir e registrar informações capazes de demonstrar a existência de crimes e a responsabilidade do Estado durante a ditadura. As comissões da verdade foram instituídas em todos os países da América do Sul que passaram por ditaduras militares, apesar de algumas delas terem sido deflagradas já no início da transição democrática na década de 1980 e outras apenas nos últimos anos, como no caso do Brasil. Com os primeiros julgamentos da Corte IDH, em 278 1988, houve uma crescente influência do plano internacional sobre os processos domésticos. Em alguns Estados, essa referência jurisprudencial contribuiu para a transição entre o paradigma estatal de responsabilidade e o individual ante os abusos militares. Verificou-se, a partir desses julgamentos interamericanos, um reforço internacional nos esforços domésticos para anulação de leis de anistia e para a instauração de processos criminais internos ${ }^{26}$. Assim, o desenvolvimento de normas regionais e jurisprudência interamericana relativas à justiça de transição, em momento posterior à deflagração dos processos internos, foi recebido domesticamente como um reforço positivo aos esforços nacionais,

\footnotetext{
${ }^{25}$ Da mesma forma que existiam diferenças regionais nos padrões de violações de direitos humanos durantes as "guerras sujas", consequentemente, os esforços para lidar com os abusos do passado também variaram em toda região (Engstrom, 2011). ${ }^{26}$ Existe uma exceção a ser considerada. Na Argentina, por exemplo, os processos judiciais foram iniciados pouco depois da transição, e continuam sendo realizados vinte anos depois.
} 
o que naquele momento tornou alguns sistemas judiciais internos mais permeáveis às normas do $\mathrm{SIDH}^{27}$.

De igual maneira, a emergência das ONGs de direitos humanos na América Latina foi impulsionada pela insurgência de golpes militares e a instauração de governos ditatoriais. Embora antes destes eventos houvesse importantes precursores dos movimentos dos direitos humanos na região como a Anistia Internacional, não se apontava ainda a existência de uma rede de advocacy abrangente. As primeiras ONGs ${ }^{28}$ surgem entre 1973 a 1981, voltadas para o trabalho de documentação e de denúncia de violações direitos humanos cometidas pelos governos militares. A realização deste trabalho se mostrou bastante relevante naquele momento, pois as ONGs constituíam uma das poucas fontes de autoridade no assunto capazes de produzir informações dotadas de credibilidade ${ }^{29}$. Nos anos seguintes, de 1981 a 1990, consolida-se a rede de advocacy em direitos humanos, uma vez que os contextos internacional e regional de atuação haviam mudado substantivamente, permitindo tais entidades lidarem com as questões da justiça de transição junto às organizações internacionais e regionais de direitos humanos, com a denúncia de casos perante a CIDH. É, inclusive, na questão da justiça transicional que as ONGs sul-americanas experimentaram

\footnotetext{
27 A decisão do caso Velásquez Rodríguez vs. Honduras, por exemplo, foi aplicada diretamente na Argentina, em 2001, declarando as leis "Ponto Final e "Obediência Devida” inconstitucionais. Chile e Uruguai também processaram graves violações sob a influência das decisões interamericanas. De outro lado, no caso do Brasil, o judiciário parece não ter sido tão receptivo, havendo ainda debates sobre as formas de implementação da sentença Gomes Lund e outros. Neste sentido, ver Malarino (2007).

28 America's Watch, International Human Rights Law Group, Lawyers Committee for Human Rights e Washington Office on Latin America.

29 Vale ressaltar que, neste momento, a CIDH não era vista com bons olhos perante as lutas domésticas, tendo em vista que o órgão se encontrava sob ingerência ou era até mesmo composto por membros representantes das forças militares estatais.
} 
seus mais importantes sucessos neste período, como as condenações por parte do tribunal interamericano e o apoio de importantes governos, como o dos Estados Unidos. Desde 1990 até então, as ONGs de direitos humanos nas Américas têm passado por uma fase de reorientação e restrição: como muitas das suas demandas iniciais foram incorporadas por políticas governamentais e organizações internacionais, a situação passou a ser percebida como menos dramática quando completado o processo de transição democrática. Atualmente, com diversas dificuldades, essas ONGs têm trabalhado pela permanência das questões da democracia na agenda regional, especialmente, para resolver os problemas da qualidade e do conteúdo da democracia em regimes formalmente eleitos (Sikkink, 1996; Keck Sikkink, 1998).

Em suma, as evidências fáticas e cronológicas suportam a afirmação de que a atuação decisiva dos órgãos intera280 mericanos nas questões de justiça transicional é posterior aos processos domésticos de responsabilização pelos crimes cometidos pelos militares e ao estabelecimento das redes de advocacy na região. Essa atuação decisiva posterior dos órgãos interamericanos produziu dois efeitos relevantes para o SIDH: os reconhecimentos domésticos em relação aos julgamentos interamericanos dos abusos militares, o que, em certa medida, facilitou a abertura das sociedades e dos Estados às normas do SIDH; e a parceria com as ONGs de direitos humanos para o provimento de informações críveis sobre os fatos levados a julgamento, reduzindo os custos (políticos e não políticos) das investigações in loco levadas a cabo pelo próprio sistema. Se, de um lado, a atuação posterior dos órgãos interamericanos nas questões da justiça de transição se deu, em boa medida, em razão das dificuldades para o estabelecimento institucional do sistema de direitos humanos na região, de outro, revela-se interessante pensar o envolvimento estratégico do SIDH no assunto enquanto 
ator internacional. Neste sentido, as questões da justiça de transição constituíram uma ampla janela de oportunidade para o SIDH avançar com os seus objetivos na região.

\section{Considerações finais}

Parte da literatura mais recente sobre os arranjos internacionais de direitos humanos tem se mostrado pouco otimista quanto à eficácia em modificar práticas estatais (Hathaway, 2002; Hafner-Burton; Tsutsui, 2005; Neumayer, 2005), um achado geralmente atribuído à baixa capacidade de enforcement das instituições internacionais. Este artigo, voltado para a questão do tratamento internacional da justiça de transição, demonstrou que os regimes internacionais de direitos humanos, sob determinadas condições, podem ter um papel relevante não só no processo de transformação do comportamento estatal, como também podem se apropriar estrategicamente de determinadas questões sensíveis aos Estados para se autotransformarem, visando maior autonomia e influência institucional.

As evidências apresentadas demonstram que o litígio estratégico das redes transnacionais de advocacy no SIDH produziram efeitos para além do demandado nos casos contenciosos. O estímulo à produção de processos jurídicos na Corte IDH suscitou interpretações expansivas da $\mathrm{CADH}$, norma da qual o tribunal deriva seus poderes e competências conferidos pelos Estados-partes do SIDH. Neste processo de definição de standards jurisprudenciais em matéria de justiça transicional, a Corte IDH não só enfrentou objetivamente questões relativas à justiça transicional (leis de anistia, reparação, punição, direito à verdade e à memória), como revisou seu posicionamento quanto à responsabilização estatal e lançou um dos seus mais amplos poderes, o controle de convencionalidade, na pretensão de tornar os sistemas jurídicos nacionais cada vez mais permeáveis ao SIDH. 


\section{Isabela Gerbelli Garbin Ramanzini}

é professora de Relações Internacionais da Universidade Federal de Uberlândia, onde coordena o Núcleo de Pesquisa e Estudos em Direitos Humanos. Possui doutorado pelo Instituto de Relações Internacionais da Universidade de São Paulo. Atualmente, realiza pesquisa pós-doutoral no Carr Center for Human Rights Policy, Harvard Kennedy School. Também é advogada, com experiência de litigância em justiça juvenil no Brasil.

\section{Referências}

ACEVEDO, Domingo; GROSSMAN, Claudio. 1996. The organization of American States and the protection of democracy. In: FARER, Tom. (ed.). Beyond sovereignty: collectively defending democracy in the Americas. Baltimore: John Hopkins University Press, pp. 131-149.

BASCH, Fernando. 2007. The doctrine of the Inter-American Court of Human Rights regarding States' duty to punish human rights violations and its dangers. American University Law Review, v. 23, n. 1, pp. 195-229.

BINDER, Christina. 2011. The prohibition of amnesties by the Inter-

American Court of Human Rights. German Law Journal, v. 12, n. 5, pp. 1203-1230.

BUERGENTHAL, Thomas. 2005. Remembering the early years of the InterAmerican Court of Human Rights. New York: Center for Human Rights and Global Justice.

CAVALLARO, James; BREWER, Stephanie. 2008. Reevaluating regional human rights litigation in the twenty-first century: the case of the Inter-American Court. The American Journal of International Law, v. 102, pp. 768-827.

CORTE INTERAMERICANA DE DERECHOS HUMANOS. 1990. Caso

Velásquez Rodríguez vs. Honduras: sentencia de 17 de agosto de 1990. San José: Corte Interamericana de Derechos Humanos. Série C, n. 9. Disponível em: <https://goo.gl/9oYFnw>. Acesso em: 16 mar. 2018. . 2001. Caso Barrios Altos vs. Perú: sentencia de 30 de noviembre de 2001.

San José: Corte Interamericana de Derechos Humanos. Série C, n. 87. Disponível em: <https://goo.gl/SoMzoq>. Acesso em: 16 mar. 2018. 2006. Caso Almonacid Arellano y otros vs. Chile: sentencia de 26 de septiembre de 2006. San José: Corte Interamericana de Derechos Humanos. Série C, n. 154. Disponível em: <https://goo.gl/7oCxRZ>. Acesso em: 16 mar. 2018. 
2007. Caso La Cantuta vs. Penú: sentencia de 30 de noviembre de 2007.

San José: Corte Interamericana de Derechos Humanos. Série C, n. 173. Disponível em: <https://goo.gl/KjqjHW>. Acesso em: 16 mar. 2018.

2013. Caso Bulacio vs. Argentina: sentencia de 18 de septiembre de 2013.

San José: Corte Interamericana de Derechos Humanos. Série C, n. 100.

Disponível em: <https://goo.gl/wpgYof> Acesso em: 16 mar. 2018.

ENGSTROM, Par. 2011. Anistia e o Sistema Interamericano de Direitos

Humanos. In: PAYNE, Leigh; ABRÃO, Paulo; TORELLY, Marcelo

(orgs.). A anistia na era da responsabilização: o Brasil em perspectiva

internacional e comparada. Brasília, DF; Oxford: Ministério da Justiça;

Universidade de Oxford, pp. 104-139.

ENGSTROM, Par; HURREL, Andrew. 2010. Why the human rights regime in the Americas matters? In: SERRANO, Mónica; POPOVSKI, Vesselin. (eds.). The human rights regime in the Americas: theory and reality. Tokyo: United Nations University Press, pp. 29-55.

FARER, Tom. 1997. The rise of the Inter-American human rights regime: no longer a unicorn, not yet an ox. Human Rights Quarterly, v. 19, n. 3, pp. 510-546.

FINNEMORE, Martha; SIKKINK, Kathryn. 1998. International norm dynamics and political change. International Organization, v. 52, n. 4, pp. 887-917.

GOLDMAN, Robert. 2009. History and action: the Inter-American Human Rights System and the role of the Inter-American Commission on Human Rights. Human Rights Quarterly, v. 31, n. 4, pp. 856-887.

HAFNER-BURTON, Emilie; TSUTSUI, Kiyoteru. 2005. Human rights in a globalizing world: the paradox of empty promises. American Journal of Sociology, v. 110, n. 5, pp. 1373-1411.

HATHAWAY, Oona. 2002. Do human rights make a difference? Yale Law Journal, v. 111, n. 8, pp. 1935-2042.

KECK, Margareth; SIKKINK, Kathryn. 1998. Activists beyond borders: advocacy networks in international politics. Ithaca: Cornell University Press.

LIMA, Raquel. 2012. A emergência da responsabilidade criminal individual no Sistema Interamericano de Direitos Humanos. Lua Nova, n. 86 , pp. 187-219.

LUTZ, Ellen; SIKKINK, Kathryn. 2000. International Human Rights Law and practice in Latin America. International Organization, v. 54, n. 3, pp. 633-659.

MALARINO, Ezequiel. 2007. Jurisprudencia latinoamericana sobre derecho penal internacional: un resumen. Lateinamerika Analyses, v. 18, n. 3, pp. 191-214. 
MEDINA, Cecilia. 1990. The Inter-American Comission on Human Rights and the Inter-American Court of Human Rights: reflections on a joint venture. Human Rights Quarterly, v. 12, n. 4, pp.439-464.

MEJÍA-LEMOS, Diego. 2014. On the "control de convencionalidad" doctrine: a critical appraisal of the Inter-American Court of Human Right's relevant case law. Anuario Mexicano de Derecho Internacional, v. 14, pp. 117-151.

MORAVCSIK, Andrew. 2000. The origins of human rights regimes: democratic delegation in postwar Europe. International Organization, v. 54, n. 2, pp. 217-252.

NEUMAN, Gerald. 2008. Import, export and regional consent in the Inter-American Court of Human Rights. The European Journal of International Law, v. 19, n. 1, pp. 101-123.

NEUMAYER, Eric. 2005. Do international human rights treaties improve respect for human rights? The Journal of Conflict Resolution, v. 49, n. 6 , pp. $925-953$.

O’DONNEL, Guillermo. 1986. Contrapontos: autoritarismo e democratização. São Paulo: Vértice.

RAMANZINI, Isabela. 2014. "O prometido é devido": compliance no Sistema Interamericano de Direitos Humanos. Tese de Doutorado em Relações Internacionais. São Paulo: Universidade de São Paulo.

284 SIKKINK, Kathryn. 1996. Nongovernamental organizations, democracy and human rights in Latin America. In: FARER, Tom. (ed.). Beyond sovereignty: collectively defending democracy in the Americas. Baltimore: John Hopkins University Press, pp. 150-168. . 2005. Patterns of dynamic multilevel governance and the insideroutsider coalition. In: DELLA PORTA, Donatella; TARROW, Sidney. (eds.). Transnational protest and global activism. Lanham: Rowan \& Littlefield, pp. 151-174.

2014. Norm diffusion from the global south (Seminário). São Paulo: Universidade de São Paulo.

SIKKINK, Kathryn; WALLING, Carrie. 2010. O impacto dos processos judiciais de direitos humanos na América Latina. In: REIS, Rossana (org.). Políticas de direitos humanos. São Paulo: Hucitec, pp. 94-124.

THEDE, Nancy; BRISSON, Hughes. 2011. International relations and the Inter-american System of Human Rights promotion and protection: strategic exploitation of windows of opportunity. Quebec Journal of International Law, pp. 7-36. Edição especial.

TORELLY, Marcelo. 2013. A formação da norma global de responsabilidade individual: mobilização política transnacional, desenvolvimento principiológico e estruturação em regras internacionais domésticas. Sistema Penal e Violência, v. 5, n. 2, pp. 298-318. 


\section{( ) )}

\section{IMPACTOS DA JUSTIÇA TRANSICIONAL SUL-AMERICANA NO SISTEMA INTERAMERICANO DE DIREITOS HUMANOS}

\section{ISABELA GERBELLI GARBIN RAMANZINI}

Resumo: O objetivo deste artigo consiste em examinar como o envolvimento gradual do Sistema Interamericano de Direitos Humanos (SIDH) nas questões de justiça transicional sul-americanas contribuiu para moldar parâmetros institucionais e normativos do sistema regional de direitos humanos. Serão analisados os principais movimentos da trajetória institucional dos órgãos interamericanos e os casos considerados paradigmáticos. Os resultados indicam que, na temática da justiça transicional, a atuação interamericana revela uma abordagem mais inovadora da proteção dos direitos humanos ao suscitar interpretações expansivas da Convenção Americana de Direitos Humanos, norma da qual se derivam poderes e competências conferidos pelos Estados-partes do SIDH.

Palavras-chave: Sistema Interamericano de Direitos Humanos; Justiça Transicional; Estados Sul-americanos; Redes de Advocacy.

\section{IMPACTS OF SOUTH AMERICAN TRANSITIONAL JUSTICE IN THE INTER-AMERICAN SYSTEM OF HUMIAN RIGHTS}

Abstract: The aim of this article is to examine how the gradual involvement of the Inter-American Human Rights System (IAHRS) in South American transitional justice issues has contributed to shape institutional and normative parameters of the regional human rights system. It analyzes the main movements of the institutional trajectory of Inter-American bodies and the cases considered paradigmatic. The results indicate that, in the area of transitional justice, the InterAmerican role presents a more innovative approach to the 
protection of human rights by raising expansive interpretations of the American Convention on Human Rights, a norm from which powers and competences originate, being conferred by the States members of the IAHRS.

Keywords: Inter-American Human Rights System; Transitional Justice; South American States; Advocacy Networks.

Recebido: 19/02/2015 Aprovado: 08/12/2017 